\title{
Evaluating Radial Current Measurements from CODAR High-Frequency Radars with Moored Current Meters*
}

\author{
BRIAN M. EMERY \\ Institute for Computational Earth System Science, University of California, Santa Barbara, Santa Barbara, California \\ LIBE WASHBURN \\ Institute for Computational Earth System Science and Department of Geography, University of California, Santa Barbara, \\ Santa Barbara, California \\ JACK A. HARLAN \\ Mastodon Enterprises, Lafayette, Colorado
}

(Manuscript received 18 April 2003, in final form 30 September 2003)

\begin{abstract}
The performance of a network of five CODAR (Coastal Ocean Dynamics Application Radar) SeaSonde highfrequency (HF) radars, broadcasting near $13 \mathrm{MHz}$ and using the Multiple Signal Classification (MUSIC) algorithm for direction finding, is described based on comparisons with an array of nine moorings in the Santa Barbara Channel and Santa Maria basin deployed between June 1997 and November 1999. Eight of the moorings carried vector-measuring current meters (VMCMs), the ninth had an upward-looking ADCP. Coverage areas of the HF radars and moorings included diverse flow and sea-state regimes. Measurement depths were $\sim 1 \mathrm{~m}$ for the HF radars, $5 \mathrm{~m}$ for the VMCMs, and $3.2 \mathrm{~m}$ for the ADCP bin nearest to the surface. Comparison of radial current components from $18 \mathrm{HF}$ radar-mooring pairs yielded $\mathrm{rms}$ speed differences of $7-19 \mathrm{~cm} \mathrm{~s}^{-1}$ and correlation coefficients squared $\left(r^{2}\right)$ in the range of $0.39-0.77$. Spectral analysis showed significant coherence for frequencies below $0.1 \mathrm{cph}$ (periods longer than $10 \mathrm{~h}$ ). At higher frequencies no significant coherence was found, and noise levels corresponding to $6 \mathrm{~cm} \mathrm{~s}^{-1}$ rms were evident in the radar data. Errors in the radar bearing determination were found in 10 out of 18 comparisons, with a typical magnitude of $5^{\circ}-10^{\circ}$, and a maximum of $19^{\circ}$. The effects of bearing errors on total vector currents were evaluated using a simple flow field and measured bearing errors, showing up to $15 \%$ errors in computed flow speeds, and up to $\sim 9^{\circ}$ errors in flow directions.
\end{abstract}

\section{Introduction}

Since the first observations of the Doppler spectrum of sea echo by Crombie (1955), high-frequency (HF) radars have become a common technology for studying coastal circulation processes. Decades of development have resulted in a number of HF radars capable of producing current vector maps of the coastal zone over spatial scales ranging from hundreds of meters to hundreds of kilometers, and on time intervals from tens of minutes to days. The high spatial and temporal resolution make HF radar technology suitable for aiding search and rescue operations, studying pollutant and lar-

* Partnership for Interdisciplinary Studies of Coastal Oceans Contribution Number 156.

Corresponding author address: Brian Emery, Institute for Computational Earth System Science, University of California, Santa Barbara, CA 93106-3060.

E-mail: emery@icess.ucsb.edu val dispersal (e.g., Bjorkstedt and Roughgarden 1997; Graber and Limouzy-Paris 1997), and analyzing the physical forcing of coastal flows (e.g., Shay et al. 1998).

Current-measuring HF radars can be roughly divided into two types based on the method used to determine bearing to a sector of ocean surface: beam forming and direction finding. Beam-forming radars, such as the ocean surface current radar (OSCR; Hammond et al. 1987) and Wellen radar (WERA; Gurgel et al. 1999), electronically steer a linear phased array of receive antennas toward a sector of ocean surface. Direction finding radars, such as the Coastal Ocean Dynamics Application Radar (CODAR) SeaSonde, exploit the directional properties of loop antennas to determine bearing. The SeaSonde, manufactured by Codar Ocean Sensors, Ltd., Los Altos, California, evolved out of the original CODAR developed by the National Oceanic and Atmospheric Administration's (NOAA's) Wave Propagation Laboratory (now the NOAA Environmental Technology Laboratory). The CODAR SeaSonde system 
uses a three-element crossed-loop/monopole receive antenna along with a variant of the multiple signal classification (MUSIC) algorithm (Schmidt 1986) to determine bearing. This configuration allows a deployment in a smaller area compared to a phased array. However, the system may be more sensitive to antenna response patterns, and the effect of this on surface current data is not well documented.

Many studies of HF radar surface currents have validated the fundamental HF Doppler current measurements through comparisons with in situ current measurements. Seminal studies by Stewart and Joy (1974), Barrick et al. (1977), and Frisch and Weber (1980) verified the underlying physics of the HF surface current measurement by comparisons with drifters. These were soon followed by Holbrook and Frisch (1981), Janopaul et al. (1982), and Schott et al. (1986), which included comparisons between direction-finding HF radars and moored current meters. Recent studies such as Shay et al. (1995), Graber et al. (1997), and Chapman et al. (1997) built on these earlier works by comparing OSCR with a variety of moored and shipboard measurements. While these studies increased the understanding of errors and limitations present in all HF Doppler radar current measurements, fewer studies of CODAR SeaSondes employing MUSIC for direction finding are available. Exceptions include Paduan and Rosenfeld (1996), who report comparisons of total vector currents that combined data from newer SeaSondes and an older CODAR HF radar; Hodgins (1994), which reports comparisons with drifters as well as modeled currents; and more recently, Kohut et al. (1999) and Paduan et al. (2001). This study seeks to add to the understanding of the CODAR SeaSonde and its MUSIC direction-finding algorithm.

The MUSIC algorithm has been evaluated by direct comparison with the beam-forming technique (Laws et al. 2000). In this study, simulation-based evaluations of MUSIC and comparisons with the beam-forming technique were made using system parameters of the multifrequency coastal radar (MCR). The MCR, codeveloped by the University of Michigan, the Environmental Research Institute of Michigan, and Stanford University, uses a phased array antenna similar to OSCR. The simulation models the sea echo given a description of the sea state, including the radial currents in a given range cell. This method is an effective evaluation of MUSIC, since currents are specified, and measurement errors can be directly assessed by comparison. This simulation illustrates some of the limitations of MUSIC and aids interpretation of comparisons with in situ measurements, but lacks the in situ data necessary for complete validation. Furthermore, while it is likely that the results of Laws et al. (2000) apply to CODAR HF radars, due to the proprietary nature of Codar Ocean Sensor's application of MUSIC additional verification is required.

Laws et al. (2000) simulated radial current velocity measurements (hereafter referred to as radials) from in-

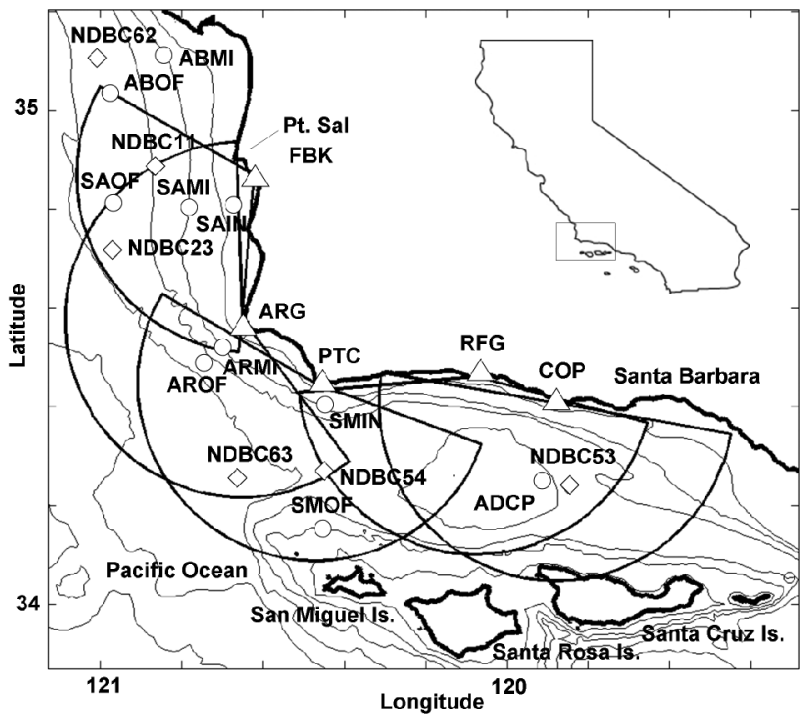

FIG. 1. Study area showing the Santa Barbara Channel and Santa Maria Basin. HF radars are indicated with triangles: Fallback-22 near Point Sal (FBK), Point Arguello (ARG), Point Conception (PTC), Refugio Beach (RFG), and Coal Oil Point (COP). Circular sectors show nominal radar ranges of $42 \mathrm{~km}$. Circles indicate moored current meters. NDBC buoys (diamonds) are abbreviated to their last two digits. The inset shows the study area relative to the California coast. Bathymetric contours show depths of 50,100, 200, 500, 1000, and $2000 \mathrm{~m}$.

dividual radars and compared them with modeled currents. We adopt a similar approach here in which observed currents are compared with in situ measurements. Other studies of the accuracy of measured radials have been reported including Stewart and Joy (1974), Collar et al. (1985), Broche et al. (1986), Essen et al. (1989), Melton (1995), and Harlan et al. (2002). Generally, these are based on one or two radars over limited time periods. In this study, five radars were deployed and record lengths up to $2.1 \mathrm{yr}$ were used.

We primarily focus on radials to isolate measurement errors arising from individual radars. Computation of total vectors requires measurements from at least two radars, a procedure that suffers from errors due to geometric dilution of precision (Chapman et al. 1997). It can also mask errors that may be present in radials, such as biases in bearing estimates. Thus, validation of the bearing determination method, in this case MUSIC, requires the analysis of radials.

Our deployment of an array of five CODAR SeaSonde HF radars coincided with a study of circulation in the Santa Barbara Channel and Santa Maria basin (Fig. 1) conducted by the Center for Coastal Studies at the Scripps Institution of Oceanography (CCS/SIO). Observations from this large array of moorings were used to evaluate the performance of the SeaSondes, including their direction-finding capability, over a wide range of time scales, and encompassing a variety of sea states and weather conditions.

This paper is organized as follows. In section 2 the 
radar and mooring deployments and data analysis procedures are discussed, results of comparisons of radial currents from the radars and current meters are presented in section 3 , section 4 is a discussion, and conclusions are in section 5 .

\section{Methods}

An array of five SeaSondes-measured hourly surface currents along the central California coast around Point Conception. Deployments began at Coal Oil Point (COP) in June 1997, followed by Point Conception (PTC) in August 1997, then Refugio (RFG) in October 1997 (Fig. 1). The fourth and fifth were deployed in November 1998 at Point Arguello (ARG) and Fallback 22 (FBK) near Point Sal. Each site consisted of a transmit antenna, a receive antenna, radar electronics, and a computer for control and datalogging. The radar electronics and computers were either housed in buildings or in weatherproof enclosures. Antennas were located as close to the ocean as possible, typically less than 20 $\mathrm{m}$ from the sea surface, to minimize signal attenuation by propagation over land.

Each radar transmitted concurrently at one of three frequencies in the $12.2-13.6-\mathrm{MHz}$ range (COP and ARG 13.49 MHz; RFG and FBK 12.2 MHz; PTC 13.59 $\mathrm{MHz}$ ), with the bend in the coastline allowing two pairs of radars to operate at the same frequency. The transmitted signals backscatter from ocean surface waves with Bragg wavelengths $(\lambda)$ of $\sim 12 \mathrm{~m}$, half the $\sim 24-\mathrm{m}$ transmitted wavelength. In the absence of any ocean current, backscattered radar signals are Doppler shifted by an amount proportional to the intrinsic deep water phase velocity of the $12-\mathrm{m}$ ocean waves. Ocean current velocity is found from the difference between the measured and intrinsic phase velocities. This measurement corresponds to the average current from the surface to a depth of order $\lambda / 4 \pi$ (Stewart and Joy 1974), or approximately $1 \mathrm{~m}$ at $13-\mathrm{MHz}$ transmit frequency. The difference in transmit frequencies used in this study may result in a roughly $10-\mathrm{cm}$ difference in the effective depth of the radar measurement $(\sim 1 \mathrm{~m}$ at $12.2 \mathrm{MHz}$, $\sim 0.9 \mathrm{~m}$ at $13.6 \mathrm{MHz}$ ). Range to a sector of ocean surface is determined using frequency modulation, which divides the coverage area into concentric circular arcs called range cells. As implemented by CODAR Ocean Sensors, Ltd., the MUSIC-based processing algorithm divides these range cells into azimuthal sectors of ocean surface and estimates the currents in each sector (Schmidt 1986; Barrick and Lipa 1997). Each sector spans $1.5 \mathrm{~km}$ in range and $5^{\circ}$ in bearing. The sector areas (shown in Fig. 7a) vary linearly from 0.2 to 5.5 $\mathrm{km}^{2}$ as range varies from 1.5 to $42 \mathrm{~km}$. Doppler spectra are computed every $10 \mathrm{~min}$ and then processed to produce radial current estimates. The 10-min radial current data are then averaged to produce hourly radial vectors for each sector. The 256-point transform used to esti- (a)

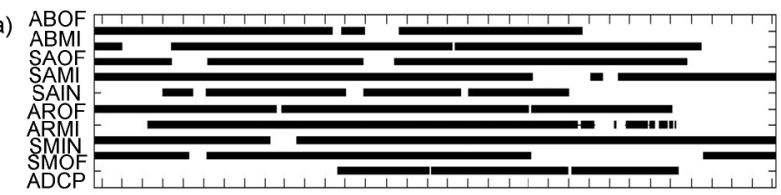

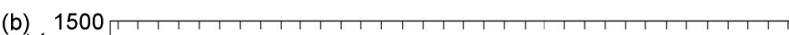
뜬 1000

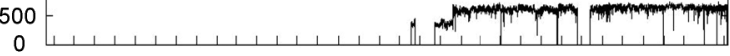

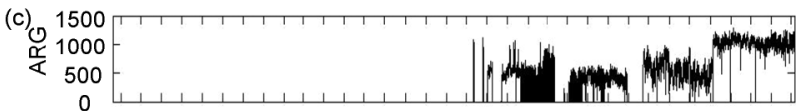

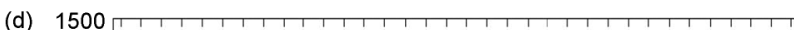
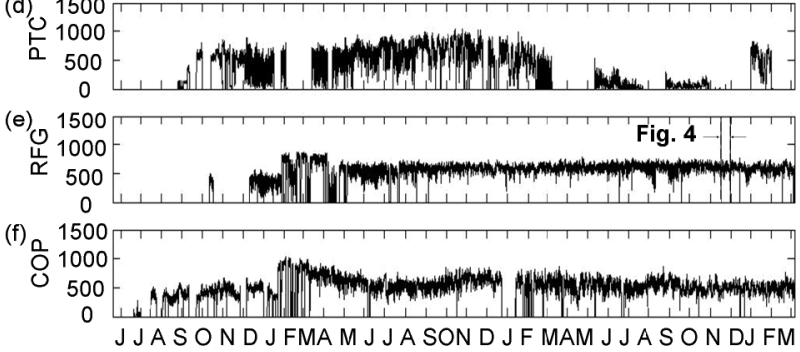

\begin{tabular}{lrr}
\hline \\
1997
\end{tabular}

FIG. 2. (a) Time lines of moored current data availability. (b)-(f) Time series of coverage, defined as the number of sectors returning data each hour, for the five HF radars. Vertical bars toward the end of the RFG time series denote the 2-week segment of Fig. 4.

mate cross spectra limits the radial speed resolution to $4 \mathrm{~cm} \mathrm{~s}^{-1}$.

The coverage area of the HF radar array included eight current meter moorings deployed in the western Santa Barbara Channel and Santa Maria basin (open circles, Fig. 1) from 1993 to 1999 by CCS/SIO. Time lines of mooring and HF radar data used for comparison are shown in Fig. 2. The CCS/SIO moorings were equipped with vector-measuring current meters (Weller and Davis 1980) at 5- and 45-m depth providing hourly averages of current velocity. The 5-m data were used for comparison with the surface HF radar data. As explained by Harms and Winant (1998), the CCS/SIO moorings were named according to location and position on the continental shelf (Fig. 1). The first two letters indicate mooring lines: AB for Avila Beach, SA for Point Sal, AR for Point Arguello, and SM for San Miguel Island. The second two letters indicate position within a mooring line: $\mathrm{OF}$ is offshore, $\mathrm{MI}$ is midshelf, and IN is in shore. For example, SAIN identifies the inshore mooring at Point Sal.

An additional mooring, designated ADCP in Figs. 1 and 2, was deployed by University of California, Santa Barbara (UCSB) investigators near the center of the Santa Barbara Channel in $\sim 650 \mathrm{~m}$ water depth, from 20 May 1998 to 12 October 1999. The mooring carried an upward-looking 1200-kHz ADCP (manufactured by R.D. Instruments, San Diego, California) mounted at 15-m depth. The ADCP measured currents over $0.5-\mathrm{m}$ bins to within $\sim 3 \mathrm{~m}$ of the sea surface every $20 \mathrm{~min}$. These data were subsequently averaged into 1-h blocks. 
TABLE 1. Summary of comparison statistics for $18 \mathrm{HF}$ radar-moored current meter pairs. The HF site name and mooring name abbreviations are described in the text.

\begin{tabular}{|c|c|c|c|c|c|c|c|c|c|c|c|c|c|}
\hline \multirow[b]{3}{*}{ HF site } & \multirow[b]{3}{*}{ Mooring } & \multirow[b]{3}{*}{ Start date } & \multirow[b]{3}{*}{ End date } & \multirow{3}{*}{$\begin{array}{c}5 \\
\text { Data } \\
\text { points } \\
\text { (hourly) }\end{array}$} & \multirow{3}{*}{$\begin{array}{c}6 \\
\text { Bearing } \\
\quad\left({ }^{\circ}\right)\end{array}$} & \multirow{3}{*}{$\begin{array}{c}\text { Range } \\
(\mathrm{km})\end{array}$} & \multirow[b]{3}{*}{$r^{2}$} & \multirow{3}{*}{$\begin{array}{l}\Delta \theta \\
\left(^{\circ}\right)\end{array}$} & \multirow{3}{*}{$\begin{array}{c}\Delta \mathrm{V}_{\mathrm{rms}} \\
\left(\mathrm{cm} \mathrm{s}^{-1}\right)\end{array}$} & \multirow{3}{*}{$\begin{array}{c}\text { Bias } \\
\left(\mathrm{cm} \mathrm{s}^{-1}\right)\end{array}$} & 12 & 13 & \multirow{3}{*}{$\begin{array}{c}14 \\
\text { Sector } \\
\text { width } \\
(\mathrm{km})\end{array}$} \\
\hline & & & & & & & & & & & \multicolumn{2}{|c|}{$V_{\mathrm{HF}}=V_{m} m+b$} & \\
\hline & & & & & & & & & & & $m$ & $b$ & \\
\hline FBK & $\mathrm{ABOF}$ & 1 Feb 1999 & 14 Nov 1999 & 125 & 299 & 36.7 & 0.59 & 16 & 11 & -2 & 0.63 & 4.3 & 3.2 \\
\hline FBK & SAOF & 1 Feb 1999 & 15 Nov 1999 & 5227 & 258 & 32.6 & 0.59 & -8 & 11 & -1 & 0.76 & 0.3 & 2.8 \\
\hline FBK & SAMI & 1 Feb 1999 & 15 Nov 1999 & 3500 & 244 & 16.7 & 0.70 & -4 & 9 & -2 & 0.75 & 0.1 & 1.5 \\
\hline FBK & SAIN & 1 Feb 1999 & 14 Nov 1999 & 2044 & 216 & 8.3 & 0.57 & -11 & 11 & -1 & 0.51 & -2.3 & 0.7 \\
\hline FBK & AROF & 1 Feb 1999 & 3 Oct 1999 & 4746 & 195 & 44.2 & 0.59 & 0 & 13 & -1 & 0.78 & -0.8 & 3.7 \\
\hline FBK & ARMI & 1 Feb 1999 & 3 Nov 1999 & 2862 & 190 & 39.4 & 0.68 & 0 & 11 & -3 & 0.76 & 0.6 & 3.4 \\
\hline ARG & SAIN & 1 Nov 1998 & 14 Nov 1999 & 457 & 355 & 25.8 & 0.52 & 10 & 14 & 6 & 0.31 & 0.5 & 2.3 \\
\hline ARG & SAMI & 1 Nov 1998 & 15 Nov 1999 & 1488 & 334 & 28.0 & 0.39 & 17 & 16 & 1 & 0.51 & 0.6 & 2.4 \\
\hline ARG & SAOF & 1 Nov 1998 & 15 Nov 1999 & 901 & 311 & 39.2 & 0.46 & 19 & 15 & 2 & 0.71 & -2.4 & 3.4 \\
\hline ARG & AROF & 1 Nov 1998 & 3 Oct 1999 & 3218 & 220 & 13.4 & 0.60 & 0 & 12 & 1 & 0.73 & -3.1 & 1.2 \\
\hline ARG & ARMI & 1 Nov 1998 & 3 Nov 1999 & 2127 & 215 & 7.7 & 0.59 & 0 & 11 & -1 & 0.64 & -2.1 & 0.7 \\
\hline ARG & SMIN & 1 Nov 1998 & 7 Mar 1999 & 913 & 137 & 26.7 & 0.62 & -7 & 19 & -4 & 0.44 & 8.4 & 2.3 \\
\hline PTC & ARMI & 1 Jun 1998 & 28 Jan 1999 & 2521 & 291 & 22.2 & 0.74 & 9 & 10 & 2 & 0.79 & -3.7 & 1.9 \\
\hline PTC & AROF* & 1 Aug 1997 & 3 Oct 1999 & 6636 & 279 & 25.2 & 0.58 & 6 & 14 & 2 & 0.76 & -4.5 & 2.2 \\
\hline PTC & AROF & 1 Jun 1998 & 28 Jan 1999 & 3717 & 279 & 25.2 & 0.71 & 1 & 10 & 3 & 0.84 & -4.3 & 2.2 \\
\hline PTC & SMOF & 1 Jun 1998 & 28 Jan 1999 & 3009 & 177 & 33.0 & 0.63 & -12 & 9 & -2 & 0.76 & -2.5 & 2.9 \\
\hline PTC & SMIN & 27 Jun 1998 & 28 Jan 1999 & 2904 & 160 & 5.7 & 0.77 & -16 & 7 & 1 & 0.85 & -1.2 & 0.5 \\
\hline RFG & ADCP & 20 May 1998 & 12 Oct 1999 & 10186 & 147 & 28.0 & 0.50 & 1 & 12 & 4 & 0.74 & -1.9 & 2.4 \\
\hline $\mathrm{COP}$ & ADCP & 20 May 1998 & 12 Oct 1999 & 6659 & 189 & 17.7 & 0.60 & -1 & 11 & -3 & 0.88 & 3.5 & 1.5 \\
\hline
\end{tabular}

* During part of the PTC-AROF time series, the PRC HF radar was not accessible for maintenance. This resulted in lower SNR than for the subset of the time series on the next line of this table.

Time series from occasional deployments of an electromagnetic current meter (model S4, manufactured by InterOcean, San Diego, California) at 5-m depth agreed closely with ADCP currents at $5 \mathrm{~m}$. The HF radar time series was compared with the time series from the ADCP bin nominally at 3.2-m depth. This was the shallowest bin consistently free from contamination due to surface reflections.

Measurements of meteorological variables are available from six National Data Buoy Center (NDBC) moorings located within the HF radar coverage area (Fig. 1). These include wind speed and direction, as well as significant wave height and period.

To compare radials from a $\mathrm{HF}$ radar, $V_{\mathrm{HF}}$, with current measurements at a particular mooring, the component of moored current velocity $V_{m}$ was computed in the direction of the HF radar,

$$
V_{m}=\mathbf{V} \cdot \mathbf{i}_{m},
$$

where the centered $\operatorname{dot}(\cdot)$ is the dot product, $\mathbf{V}$ is the mooring current velocity vector, and $\mathbf{i}_{m}$ is the unit vector pointing from the mooring toward the HF radar site. A total of 18 paired mooring-HF radar time series were available with maximum record lengths exceeding $1 \mathrm{yr}$ (Fig. 2 and Table 1).

To examine performance of individual radars, various statistics for each pair of radar and mooring time series were computed. The square of the correlation coefficient $\left(r^{2}\right)$ was computed between $V_{m}$ and $V_{\mathrm{HF}}$ for the sector containing the mooring and for sectors surrounding the mooring. Typically, a single radar sector entirely con- tained the mooring watch circle $(50-300 \mathrm{~m}$ in radius depending on water depth for the CCS/SIO moorings; $750 \mathrm{~m}$ for the ADCP mooring). To quantify measurement errors and differences, and to compare with previous studies, the rms differences between $V_{m}$ and $V_{\mathrm{HF}}$ were computed as

$$
\Delta V_{\mathrm{rms}}=\left\{\frac{1}{N} \sum_{i}\left[\left(V_{m}-\bar{V}_{m}\right)-\left(V_{\mathrm{HF}}-\bar{V}_{\mathrm{HF}}\right)\right]^{2}\right\}^{1 / 2},
$$

where $N$ is the number of data points, and overbars indicate time averages. Additionally, comparisons were made by computing the bias,

$$
\text { bias }=\bar{V}_{\mathrm{HF}}-\bar{V}_{m} \text {, }
$$

and least squares fit, computed such that

$$
V_{\mathrm{HF}}=V_{m} m+b \text {, }
$$

where $m$ and $b$ represent the slope and $y$ intercept, respectively. Power and coherence spectra were also computed to examine differences versus frequency between the HF radar and moored time series.

\section{Results}

\section{a. Correlation and radial velocity differences}

Time series of $V_{\mathrm{HF}}$ and $V_{m}$ typically showed strong tidal variations as in the 2-week example from FBKSAMI (Fig. 3a). The time series were clearly similar and exhibited significant correlation for this short interval ( $r^{2}=0.81, N=314$; Fig. $\left.3 \mathrm{~b}\right)$. Table 1 summarizes 

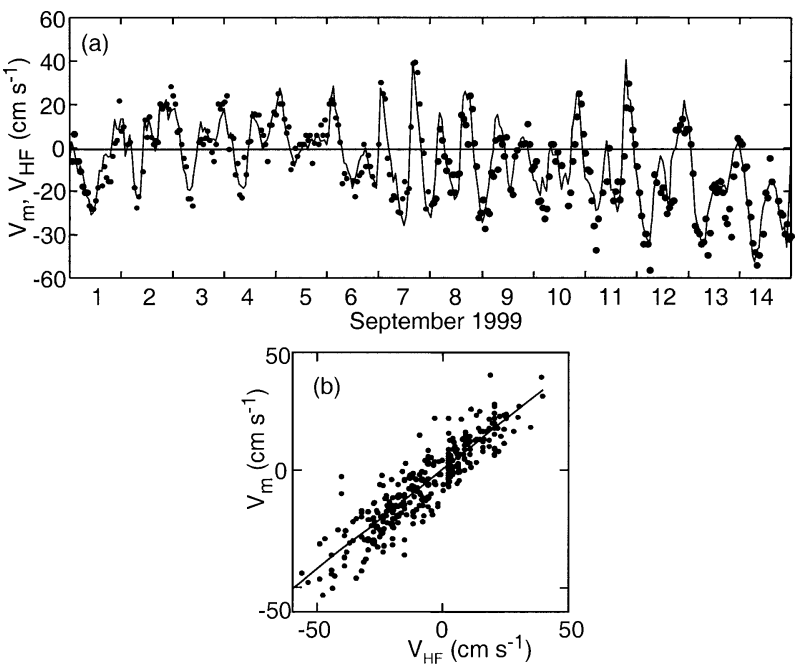

FIG. 3. (a) Time series of radial currents $V_{m}$ from mooring SAMI (solid line) and radial currents $V_{\mathrm{HF}}$ from the FBK radar (dots) for 114 Sep 1999. (b) Scatterplot of $V_{m}$ vs $V_{\mathrm{HF}}$ from (a). Here $V_{m}$ and $V_{\mathrm{HF}}$ shown are significantly correlated with $r^{2}=0.81, N=314$, and are related such that $V_{m}=0.846 V_{\mathrm{HF}}+0.535$.

the statistical comparisons between $V_{\mathrm{HF}}$ and $V_{m}$ for all HF radar-mooring pairs over much longer time periods. Variations in lengths of the comparison periods (columns 3 and 4) mainly resulted from changing coverage for some of the radars due to hardware problems. Values of $r^{2}$ fell in the range $0.39-0.77$ (column 8), and $\Delta V_{\text {rms }}$ ranged from 7 to $19 \mathrm{~cm} \mathrm{~s}^{-1}$ (column 10). Biases (column 11) were typically less than $2 \mathrm{~cm} \mathrm{~s}^{-1}$, with a maximum of $6 \mathrm{~cm} \mathrm{~s}^{-1}$. Slopes $m$ of regression lines were in the range $0.31-0.88$ with intercepts $b$ in the range -4.5 to $8.4 \mathrm{~cm} \mathrm{~s}^{-1}$ (columns 12 and 13).
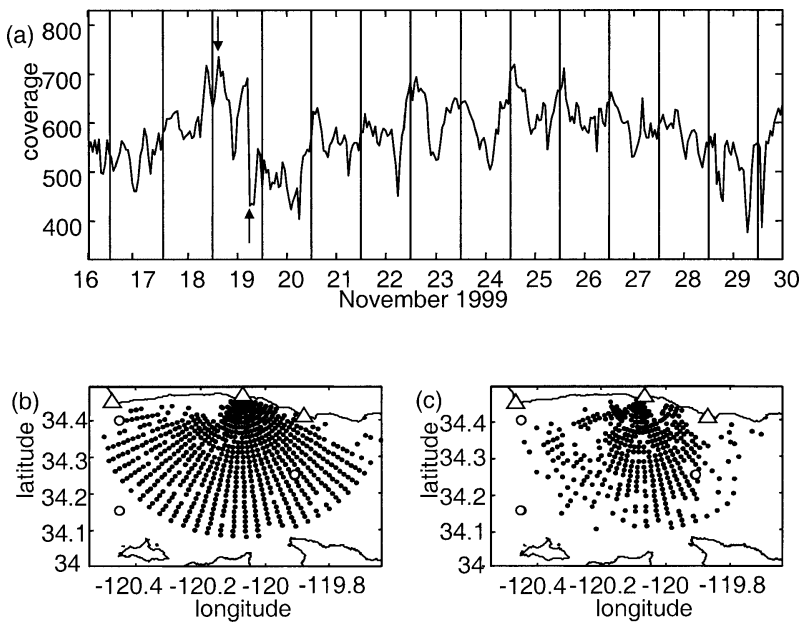

FIG. 4. (a) Time series of coverage at RFG for 16-30 Nov 1999 showing strong variations over a broad range of time scales including a prominent diurnal component. Coverage was defined as the number of sectors returning radial currents each hour. Vertical lines indicate local noon. Arrows show times of (b) high coverage at 2300 UTC 18 Nov 1999, and (c) low coverage at 1400 UTC 19 Nov 1999. Dots indicate sectors returning radial velocity measurements.
Good operating conditions and high signal-to-noise ratio (SNR; $>25$ ) resulted in $\Delta V_{\text {rms }}$ in the range 9-13 $\mathrm{cm} \mathrm{s}^{-1}$, and $r^{2}$ in the range $0.59-0.70$ for the FBK radar (Table 1). Comparable $\Delta V_{\text {rms }}\left(7-10 \mathrm{~cm} \mathrm{~s}^{-1}\right)$ and $r^{2}$ (0.63-0.77) were found for the PTC radar for the period 1 June 1998-28 January 1999 when unlimited access to the site allowed routine maintenance and repair. Before and after this period, hardware problems reduced the performance of the PTC radar. This is indicated for the PTC-AROF pair by the lower $r^{2}(0.58)$ and greater $\Delta V_{\text {rms }}\left(14 \mathrm{~cm} \mathrm{~s}^{-1}\right)$ for the full time series, 1 August 1997-3 October 1999 (Table 1). Similar results were found using the full time series when PTC was paired with the other moorings of Table 1 (results not shown). The greatest $\Delta V_{\text {rms }}\left(11-19 \mathrm{~cm} \mathrm{~s}^{-1}\right)$ and lowest $r^{2}(0.39-$ 0.62 ) were observed between the ARG radar and surrounding moorings, most likely due to reduced SNR (occasionally $<20$ ) caused by antenna and cable problems.

The longest time series were obtained from the ADCP mooring and the RFG and COP radars (10 186 and 6659 $\mathrm{h}$ of overlapping data, respectively). These radars had consistently high signal-to-noise ratios during the mooring deployment period, but with $r^{2}(0.50-0.60)$ and $\Delta V_{\text {rms }}\left(11-12 \mathrm{~cm} \mathrm{~s}^{-1}\right)$ comparable to the other pairs. This may have resulted from the large watch circle of the ADCP mooring (radius $\sim 750 \mathrm{~m}$ ). Occasional mooring GPS fixes were adequate enough to determine the mooring watch circle, but too sparse to account for horizontal mooring motion in the ADCP data.

\section{b. Coverage variations}

An overall indicator of radar performance is spatial coverage over time. Coverage is defined as the number of sectors returning radials each hour (Figs. 2b-f). Some moorings were near, or just beyond, the range limits of the radars $(42 \mathrm{~km})$, or near the edge of angular coverage (e.g., ABOF in Fig. 1). Angular coverage typically extended to within a few degrees of the surrounding coastline. Consistently high coverage obtained at FBK corresponded to high SNRs, low $\Delta V_{\text {rms }}$, and high $r^{2}$. At ARG, low, intermittent coverage corresponded to lower $r^{2}$ and higher $\Delta V_{\text {rms }}$. An increase in coverage at ARG in November 1999, after the comparison period, resulted from antenna and cable replacement. Causes of coverage variability include power outages, antenna collapse, or other hardware failures. For example, at RFG in April 1998 animals bit partially through the transmit cable causing poor transmission, lower signal-to-noise ratios, and frequent signal loss. Transmit and receive cables were then enclosed in electrical conduit. Coverage variations may also result from changing noise sources or variations in the environment around the radar antennas (Prandle et al. 1993).

High-frequency coverage variations were apparent in the time series (Figs. 2b-f). An expanded view of a 2week period of the RFG time series (Fig. 4a) illustrates 
a strong diurnal component, which was observed in the coverage time series from all sites. Hourly coverage maps (Figs. 4b, c) show that the diurnal variation resulted from patchiness in coverage, as well as extensions and contractions of range, as observed by Prandle et al. (1993) and Paduan and Rosenfeld (1996). For RFG the diurnal coverage reached a maximum around 1400 local time each day and a minimum about $12 \mathrm{~h}$ later (Fig. $4 a)$. No significant squared coherence $\left(\gamma^{2}\right)$ was found between RFG coverage and wind speed from NDBC buoy 46053 (NDBC 53 in Fig. 1), except at a narrow peak centered on $1 \mathrm{cpd}$, where $\gamma^{2}$ reached 0.48 . This peak may have been coincidental, resulting from the diurnal sea breeze and the diurnal tidal component. In addition to diurnal variations, large fluctuations extending over a range of time scales were evident in the coverage record and often obscured the diurnal pattern.

\section{c. Spectral analysis}

To examine variance in the current measurements versus frequency, power spectra were computed for time series of $V_{\mathrm{HF}}$ and $V_{m}$, using $V_{\mathrm{HF}}$ from the sector that contained $V_{m}$. Rotary spectra (Gonella 1972) of total current vectors were also computed for a selected time series from SAMI, ARG, and FBK, for comparison with previous studies of radar performance. Power spectra of $V_{\mathrm{HF}}$ and $V_{m}$ for all radar-current meter pairs were computed, but results from SAMI, ARG, and FBK are presented because their time series had the fewest gaps. Other records typically had more missing data ( $30 \%)$.

Gaps appear to be a characteristic of direction-finding radars, or the MUSIC algorithm. They may result from the inability of the MUSIC algorithm to resolve all angles at all times for a given range cell, thereby leaving some sectors with no data (Paduan and Rosenfeld 1996). Gaps in time series of $V_{\mathrm{HF}}$ were filled prior to computing spectra. For $V_{\mathrm{HF}}$ time series from FBK measured at the sector coinciding with SAMI, approximately $11 \%$ of the data was missing. The same sector observed by ARG had $20 \%$ missing. Gaps in $V_{\mathrm{HF}}$ time series were filled by first computing a time series of the spatial mean of surrounding $\mathrm{HF}$ radar sectors. Then, a linear least squares fit was computed between this time series and that from the sector nearest the mooring. The fitted line was used to predict the values in the gaps. For the FBK spectra, this procedure reduced missing points from 431 to 13 , out of 3758 contiguous hours from 0000 UTC 1 October 1999 to 1300 UTC 5 March 2000. For the ARG spectra, missing points were reduced from 575 to 12 out of 2843 contiguous hours from 0100 UTC 8 November 1999 to 1200 UTC 5 March 2000.

Spectra of $V_{\mathrm{HF}}$ from FBK and $V_{m}$ from SAMI agree well for frequencies less than 0.1 cycles $\mathrm{h}^{-1}$ (cph), and the diurnal $\left(\mathrm{K}_{1}, 23.93-\mathrm{h}\right.$ period) and semidiurnal $\left(\mathrm{M}_{2}\right.$, 12.42-h period) tidal peaks are well resolved (Fig. 5a). Above $\sim 0.2 \mathrm{cph}$ the $V_{\mathrm{HF}}$ spectrum departs from the $V_{m}$ spectrum, which has a slope in the range -3 to -2
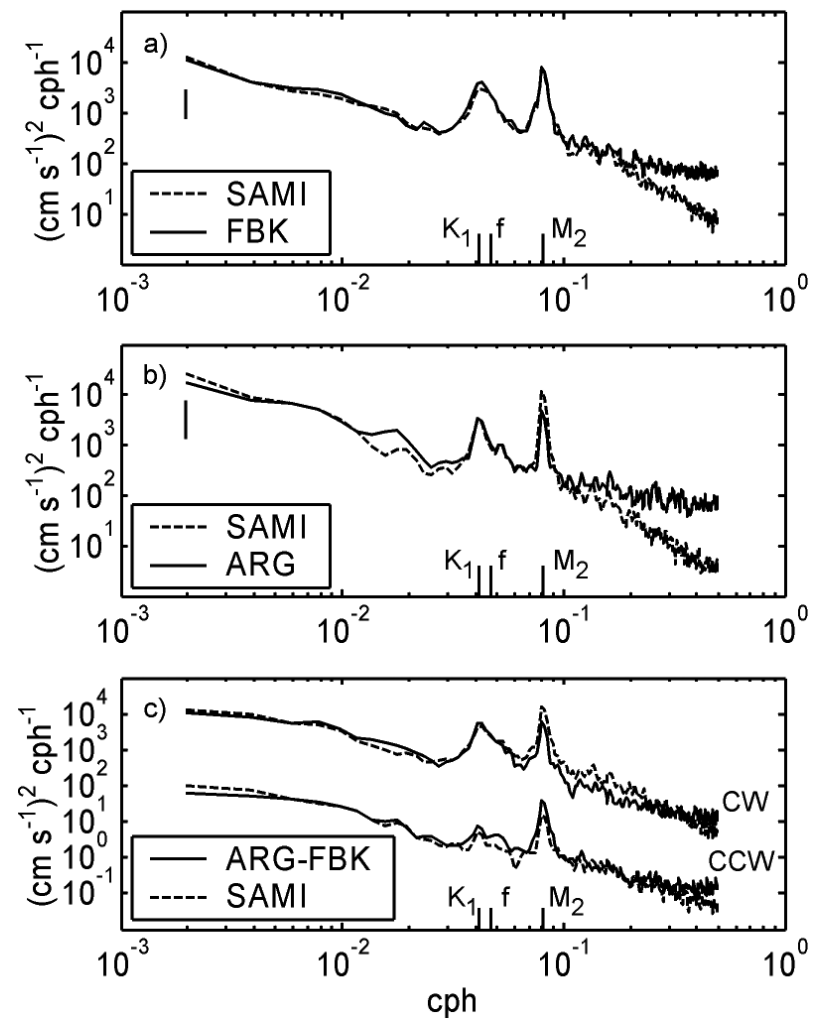

FIG. 5. (a) Power spectra of $V_{m}$ from SAMI and $V_{\mathrm{HF}}$ from FBK, with $95 \%$ confidence interval. (b) As in (a), but for SAMI and ARG. (c) Rotary spectra of total velocities from ARG-FBK and SAMI. CCW spectra have been offset by $10^{-2}$ for clarity. The $K_{1}$ tidal, $M_{2}$ tidal, and inertial frequencies are shown in all panels.

(mean $=-2.6)$. The flattening of the $V_{\mathrm{HF}}$ spectrum above $0.3 \mathrm{cph}$, suggesting white noise, is typical of spectra from COP, RFG, and PTC (data not shown). If the white noise level for FBK of $\sim 70 \mathrm{~cm}^{2} \mathrm{~s}^{-2} \mathrm{cph}^{-1}$ (average of FBK $V_{\mathrm{HF}}$ spectrum between 0.3 and $0.5 \mathrm{cph}$ ) is extrapolated over the entire bandwidth, about $16 \%$ of total variance, the rms level corresponding to the noise is $6 \mathrm{~cm} \mathrm{~s}^{-1}$. A similar comparison for ARG and SAMI spectra shows separation at about $0.1 \mathrm{cph}$ (Fig. 5b) with a comparable noise level above $0.3 \mathrm{cph}$. For ARG the extrapolated noise also yields an rms velocity of $6 \mathrm{~cm}$ $\mathrm{s}^{-1}$, corresponding to $19 \%$ of the total variance. Following Chapman et al. (1997), the contribution of this noise to the tidal band is estimated. For $V_{\mathrm{HF}}$ spectra of Fig. 5a, computed with a 512-point transform, the $\mathrm{M}_{2}$ tidal peak spreads across 11 frequency bins covering 0.07-0.09 $\mathrm{cph}$. The corresponding rms tidal fluctuation is $7.7 \mathrm{~cm} \mathrm{~s}^{-1}$. The rms level corresponding to the noise is about $1.2 \mathrm{~cm} \mathrm{~s}^{-1}$, or about $15 \%$ of the $\mathrm{M}_{2}$ tidal variance.

Gaps were less frequent for total velocity vectors because radials from several sectors were used to compute them. For total vectors using radials from FBK and ARG from 0000 UTC 8 November 1999 to 1200 UTC 5 March 2000 , only $11 \mathrm{~h}$ of data were missing. Total ve- 

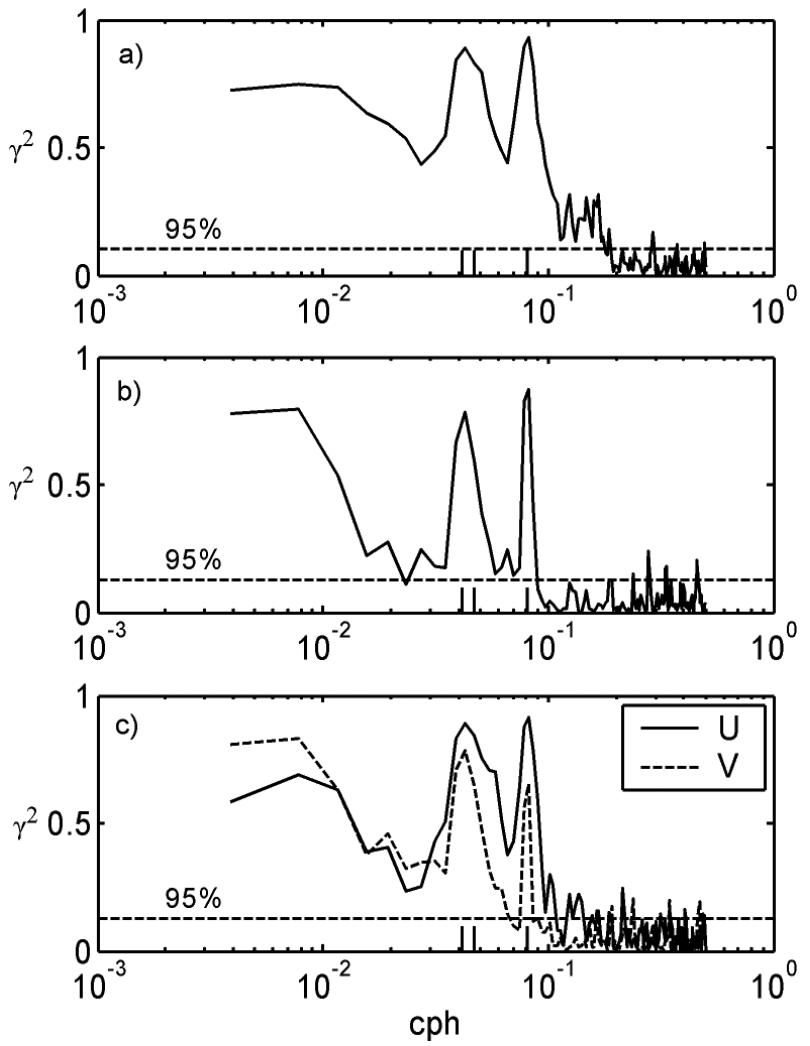

FIG. 6. (a) Squared coherence $\gamma^{2}$ between $V_{m}$ from SAMI and $V_{\mathrm{H}}$ from FBK. Dotted line shows 95\% significance threshold. (b) As in (a), but for SAMI and ARG. (c) $\gamma^{2}$ for east $(U)$ and north $(V)$ velocity components between SAMI and ARG-FBK. The $\mathrm{K}_{1}$ tidal, $\mathrm{M}_{2}$ tidal, and inertial frequencies are shown in all panels.

locity components $U$ (east) and $V$ (north) were computed from all radials within a 3 -km-radius circle centered on a grid point near SAMI, using the least squares fit method of Gurgel (1994).

Clockwise (CW) rotary spectra from SAMI and ARG-FBK show similar levels at the diurnal $\left(\mathrm{K}_{1}\right)$ tidal and lower frequencies (Fig. 5c). In the range 0.06-0.25 cph, including the semidiurnal tidal band, the $\mathrm{CW}$ spectra for SAMI has somewhat higher variance. This contrasts with counterclockwise (CCW) rotary spectra, which show slightly higher variance in the HF radar time series at the two tidal frequencies. Both $\mathrm{CW}$ and CCW spectra from ARG-FBK flatten at about $0.3 \mathrm{cph}$, consistent with the radial spectra of Figs. 5a and 5b. Above $0.1 \mathrm{cph}$ the slope of the ARG-FBK spectra is flatter than that for SAMI, which trends toward $1 \mathrm{~cm}^{2}$ $\mathrm{s}^{-2} \mathrm{cph}^{-1}$ at $1 \mathrm{cph}$. This result is similar to the rotary spectra of CODAR data in Fig. 3 of Paduan and Rosenfeld (1996). Flattening above about $1 \mathrm{cph}$ is also evident in rotary spectra reported by Shay et al. (1995), as the OSCR's 1.5-cph Nyquist frequency is approached.

Squared coherence spectra $\gamma^{2}$ were computed between pairs of time series to examine correlation versus frequency. In Fig. 6a $\gamma^{2}$ for $V_{\mathrm{HF}}$ from FBK and $V_{m}$ from
SAMI are shown for the same time series used to compute spectra of Fig. 5a. The similar power spectral levels in Figs. 5a and 5b correspond to statistically significant coherent motions up to frequencies of about $0.2 \mathrm{cph}$, where $\gamma^{2}$ drops below the $95 \%$ threshold. Lower overall $\gamma^{2}$ is obtained for the ARG-SAMI pair (Fig. 6b), which drops below the $95 \%$ threshold at $0.09 \mathrm{cph}$ and briefly at about $0.02 \mathrm{cph}$. In Fig. 6c, $\gamma^{2}$ between $U$ and $V$ from ARG-FBK and SAMI were significant below $0.1 \mathrm{cph}$ including the $K_{1}$ and $M_{2}$ tidal bands. Phase spectra for Figs. 6a-c (not shown) were nearly zero at all frequencies where $\gamma^{2}$ was above the $95 \%$ threshold.

\section{d. Bearing offsets}

To evaluate the CODAR SeaSonde direction-finding capability, $r^{2}$ was computed between $V_{m}$ and $V_{\mathrm{HF}}$, using $V_{\mathrm{HF}}$ from sectors containing and surrounding the moorings. In the absence of direction-finding errors, one would expect maximum $r^{2}$ at sectors containing the moorings. However, in 10 of the 18 comparisons the peak in $r^{2}$ was displaced in bearing from the sector where $V_{m}$ was measured. Comparisons using $\Delta V_{\text {rms }}$ produced similar results. To quantify the result, the displacement in bearing, or bearing offset $\Delta \theta$ is defined as

$$
\Delta \theta=\theta_{r}-\theta_{m}
$$

where $\theta_{r}$ is the bearing to the center of the sector with maximum $r^{2}$ and $\theta_{m}$ is the bearing to the mooring. Positive $\Delta \theta$ indicates that the sector with maximum $r^{2}$ is displaced clockwise from the mooring.

An example of a large bearing offset, $\Delta \theta=-16^{\circ}$, is shown for PTC-SMIN (Fig. 7a). The maximum in $r^{2}$ was broad, but its peak was clearly offset from SMIN as indicated by $r^{2}$ profiles along constant range lines of $4.5,6.0$, and $7.5 \mathrm{~km}$ (Figs. $7 \mathrm{~b}, \mathrm{c}, \mathrm{d}$, respectively). The maximum $r^{2}$ occurred in the same range cell as SMIN, such that the offset was in bearing only. A small bearing offset was found for COP-ADCP, with $\Delta \theta=-1^{\circ}$ (Fig. $8 \mathrm{a})$. Here the sector with maximum $r^{2}$ contained the large mooring watch circle, and a broad maximum extended over bearing and range (Figs. 8b-d). Column 9 of Table 1 shows $\Delta \theta$ for each of the $18 \mathrm{HF}$ radarmooring pairs; $\Delta \theta$ ranged from $-16^{\circ}$ to $19^{\circ}$ with an average absolute value of $7^{\circ}$, although $\Delta \theta$ could only be determined to within the $5^{\circ}$ sector width. Three of the HF radars (PTC, ARG, and FBK) had coverage areas that including more than one mooring (Fig. 1). For these radars, $\Delta \theta$ was not constant, but changed at different locations around the radars (Table 1). For example, at ARG, $\Delta \theta$ was a maximum of $\Delta \theta=19^{\circ}$ at $311^{\circ}$, and a minimum of $\Delta \theta=0^{\circ}$ at $220^{\circ}$. At FBK, $\Delta \theta$ reached a minimum of $-11^{\circ}$ at $216^{\circ}$ then increased to $16^{\circ}$ at $299^{\circ}$. At PTC, with four moorings located at different bearings in its coverage area, $\Delta \theta$ increased roughly monotonically with bearing, from $\Delta \theta=-16^{\circ}$ at bearing $160^{\circ}$ to $\Delta \theta=9^{\circ}$ at $291^{\circ}$ (Table 1 , columns 6 and 9 ). 

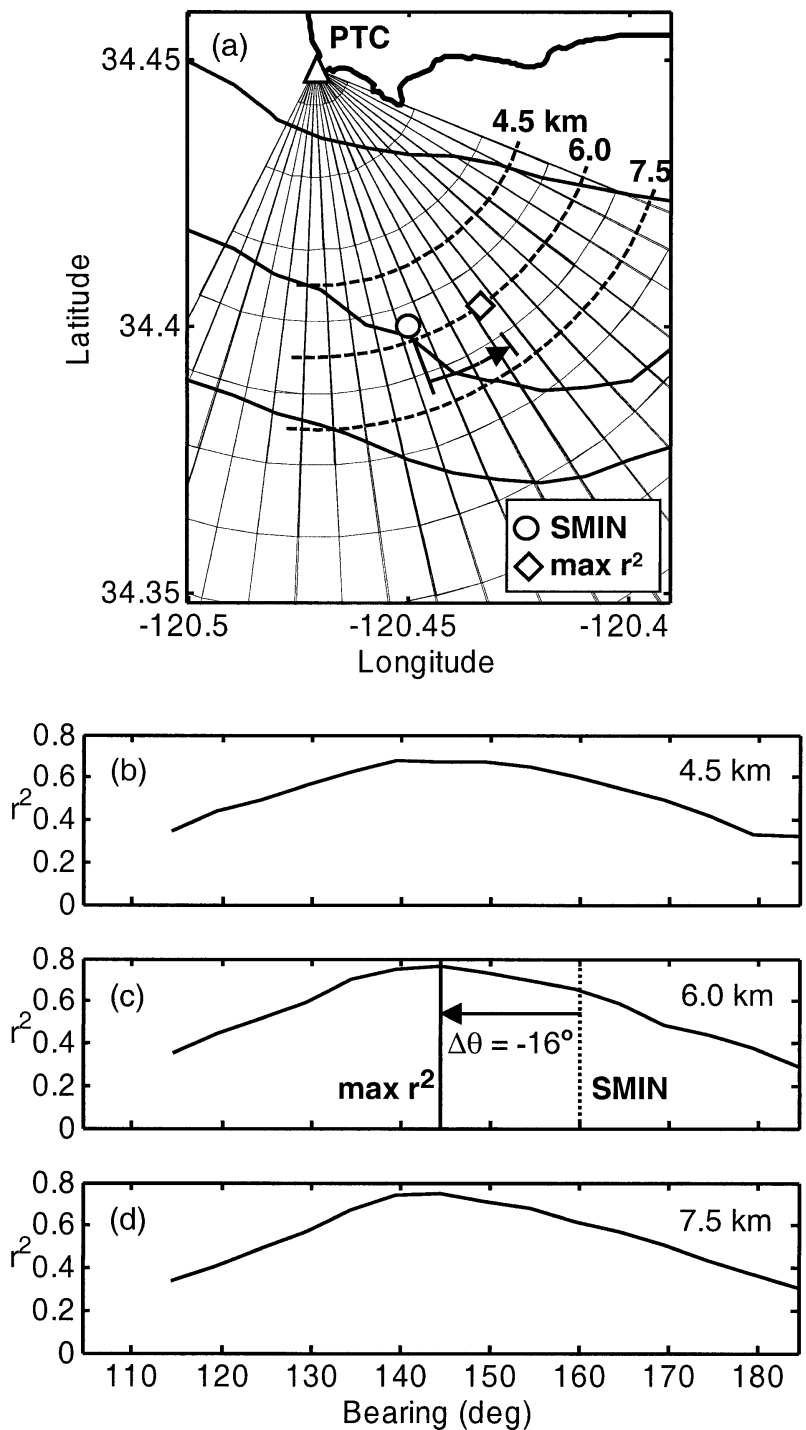

FIG. 7. (a) Map shows PTC radar (triangle) and SMIN mooring (circle), with HF radar measurement sectors and bathymetric contours at $50,100,200$, and $300 \mathrm{~m}$. Here $V_{\mathrm{HF}}$ was computed for sectors 1.5 $\mathrm{km}$ in radius by $5^{\circ}$ in azimuth, and $V_{m}$ was measured at SMIN. Diamond indicates sector with the highest $r^{2}$ between $V_{\mathrm{HF}}$ and $V_{m}$. Arrow shows $\Delta \theta$ between mooring location and sector with highest $r^{2}$. Dashed arcs show locations of $r^{2}$ profiles in (b), (c), and (d). Profiles of $r^{2}$ between $V_{\mathrm{HF}}$ and $V_{m}$ are shown along ranges of (b) 4.5, (c) 6.0, and (d) $7.5 \mathrm{~km}$.

\section{Discussion}

\section{a. Coverage variability}

Changes in range and azimuthal coverage spanned a range of time scales, with a prominent diurnal variation, consistent with results of Prandle et al. (1993) and Paduan and Rosenfeld (1996). A possible source is the wellknown diurnal cycle in the ionosphere's lowest layer, the D region (e.g., Davies 1990), which allows radio waves from great distances $\left(\sim 10^{3}\right.$ to $\left.10^{4} \mathrm{~km}\right)$ to become external noise to coastal HF radars, leading to lower
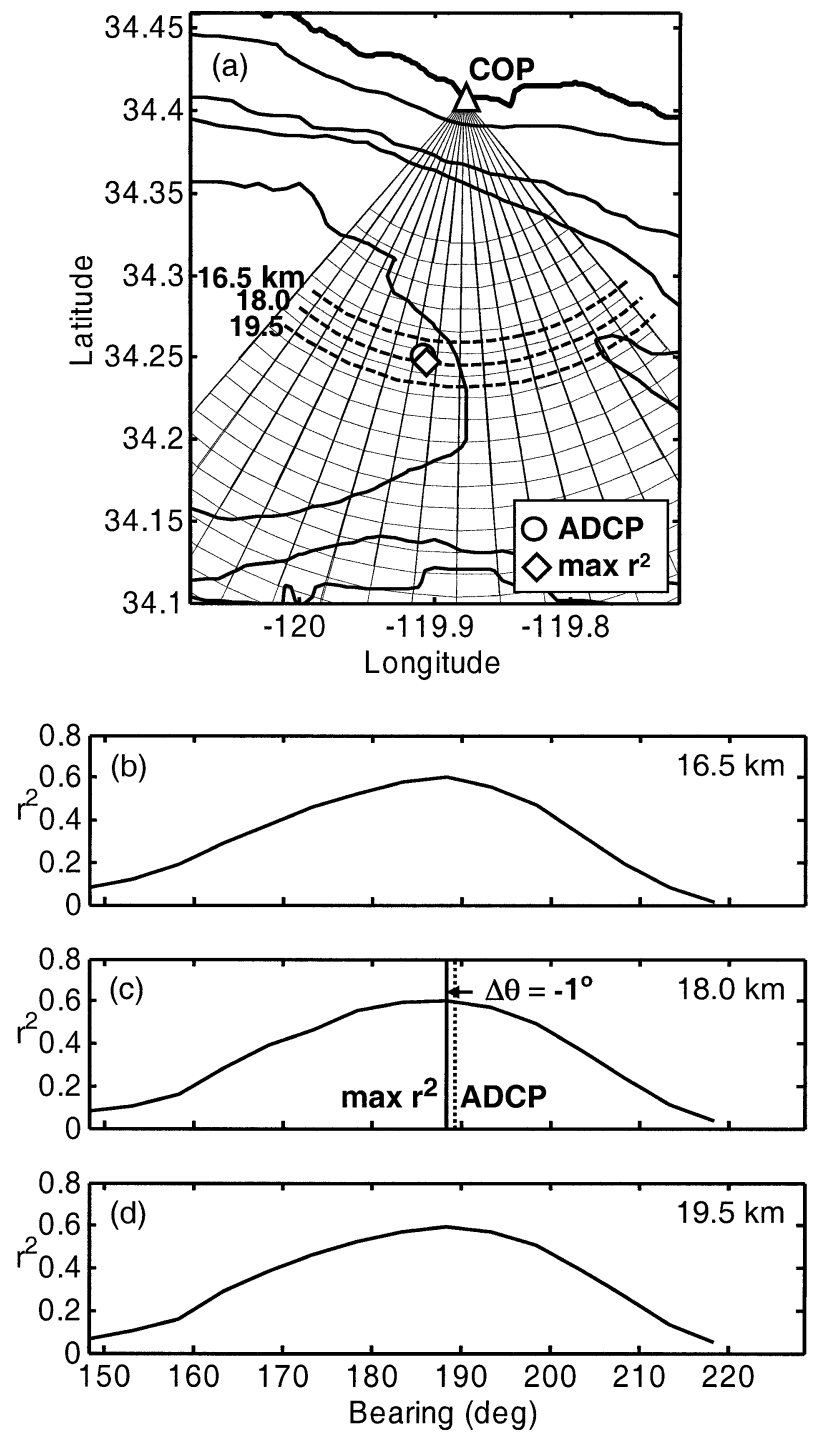

FIG. 8. (a) As in Fig. 7, but for COP radar (triangle) and ADCP mooring (circle). Profiles of $r^{2}$ between $V_{\mathrm{HF}}$ and $V_{m}$ are shown along ranges of (b) 16.5, (c) 18.0, and (d) $19.5 \mathrm{~km}$.

SNR and poor coverage. As an example, an investigation of unusually strong diurnal coverage variations and poor SNR at PTC revealed foreign media broadcasts as the cause. Azimuthal coverage variability has been shown to depend on the distribution of Bragg scattering ocean waves. Laws et al. (2000) used simulated backscatter data for a phased array receive antenna to demonstrated that the MUSIC algorithm produced areas of low coverage when the SNR was $12 \mathrm{~dB}$ lower than adjacent areas. Such areas result when the wind direction is perpendicular to the radar look direction, and when the radar coverage area is partially shadowed from the wind by land formations. These regions of decreased sea echo, and lower SNR, are likely a significant source of azimuthal coverage variability for our study region 
due to the spatial variability in wind speed in the region (Dorman and Winant 2000).

\section{b. Velocity differences}

Values of $\Delta V_{\text {rms }}$ in Table 1 are comparable in range (7-19 $\mathrm{cm} \mathrm{s}^{-1}$ ) to $\mathrm{rms}$ differences in radial and $U, V$ components reported elsewhere. Shay et al. (1995) found rms differences in $U, V$ of $11-15 \mathrm{~cm} \mathrm{~s}^{-1}$ for a 27-day deployment on the inshore boundary of the Gulf Stream, by comparing 25.4-MHz OSCR (effective sampling depth $\sim 0.5 \mathrm{~m}$ ) with current meters at 9.5- and 13.8-m depths. Paduan and Rosenfeld (1996) reported rms differences of 6.2 and $10.8 \mathrm{~cm} \mathrm{~s}^{-1}$ near Monterey Bay comparing 48-h low-passed $U, V$ components from a CODAR array with ADCP data at 9-m depth. The array consisted of two CODAR SeaSondes operating near $12.5 \mathrm{MHz}$, and one older CODAR operating at 25.4 MHz. Chapman et al. (1997) found rms $U, V$ differences between 25.4-MHz OSCR and four shipborne current meters in the range $9-16 \mathrm{~cm} \mathrm{~s}^{-1}$, including measurements made near 5-m depth, where rms differences range from 11 to $15 \mathrm{~cm} \mathrm{~s}^{-1}$. When combined with the results of Shay et al. (1998), who found rms differences of 7-9 $\mathrm{cm} \mathrm{s}^{-1}$ between VMCMs (4- and 6-m depth) and a 25.4-MHz OSCR in a 29-day deployment off the North Carolina coast, these studies suggest an envelope of rms $U, V$ differences between $\mathrm{HF}$ radars and $\sim 5 \mathrm{~m}$ currents of $7-15 \mathrm{~cm} \mathrm{~s}^{-1}$. Similar results for radials were found by Kosro et al. (1997), with 12.6-16.2 $\mathrm{cm} \mathrm{s}^{-1}$ from a 7-m ADCP and an OSCR, and Kohut et al. (1999), with $6.7 \mathrm{~cm} \mathrm{~s}^{-1}$ between a 4.5-m ADCP and a SeaSonde. For comparison, rms differences in $U$, $V$ between ARGFBK and SAMI from 1 February 1999 to 14 November 1999 are $10 \mathrm{~cm} \mathrm{~s}^{-1}(U)$ and $14 \mathrm{~cm} \mathrm{~s}^{-1}(V)$, while $\Delta V_{\mathrm{rms}}$ between FBK and SAMI is $9 \mathrm{~cm} \mathrm{~s}^{-1}$ for the same period.

Chapman et al. (1997) distinguished between measurement errors resulting from instrument noise, and measurement differences, produced by the subtraction of two current measurements. Measurement differences include errors as well as actual current velocity differences resulting from factors such as different spatial averaging and measurement over different depths. Graber et al. (1997) considered several physical processes contributing to measurement differences. For example, during a summertime period of low winds and waves, they compared currents from an OSCR and a current meter at 5-m depth and attributed 17\%-22\% of the rms difference to Ekman flow, Stokes drift, and baroclinic currents.

Wind-driven shear in our study area is likely an important contributor to measured differences, especially outside the Santa Barbara Channel. Observations from NDBC 53 , located $\sim 6 \mathrm{~km}$ east of the ADCP mooring (Fig. 1), indicate atmospheric conditions comparable to those observed by Graber et al. (1997). NDBC 53 wind speeds averaged $4.8 \pm 3.0 \mathrm{~m} \mathrm{~s}^{-1}$, similar to $4.4 \pm 2.1$ $\mathrm{m} \mathrm{s}^{-1}$ reported in their Table 6 . Current shear between
ADCP bins at 3.2 and $8.2 \mathrm{~m}$ was typically less than 4 $\times 10^{-4} \mathrm{~s}^{-1}$, with occasional episodes in the range $0.5-$ $1 \times 10^{-3} \mathrm{~s}^{-1}$. There are somewhat lower than shear levels observed by Graber et al. (1997). Observations from NDBC buoys near the VMCM moorings outside the Santa Barbara Channel (Fig. 1) show much higher mean wind speeds. NDBC 63 and 54 observed mean wind speeds of $7-8 \mathrm{~m} \mathrm{~s}^{-1}$ during the study period. Southwest of our study area Richman et al. (1987), using a drifting string of VMCMs, measured near-surface current shears of order $10^{-2} \mathrm{~s}^{-1}$ during a high wind event $\left(>12 \mathrm{~m} \mathrm{~s}^{-1}\right)$. High wind events such as this frequently occur at NDBC 23, 63, and 54. During the study period, winds exceeding $10 \mathrm{~m} \mathrm{~s}^{-1}$ were observed at these buoys $21 \%, 17 \%$, and $34 \%$ of the time, respectively.

Following Richman et al. (1987), wind-induced shear was estimated near the sea surface using the log layer model,

$$
\Delta u_{\log }=u_{*} \kappa^{-1} \ln \left(z_{1} / z_{0}\right),
$$

where $\Delta u_{\log }$ is the speed difference over depths $z_{1}$ and $z_{0}, u_{*}$ is

$$
u_{*}=(\tau / \rho)^{1 / 2},
$$

where $\tau$ is the wind stress, and $\kappa$ is von Kármán's constant $(\kappa=0.4) ; z_{1}$ and $z_{0}$ were 1 and $5 \mathrm{~m}$, corresponding to the nominal HF radar sampling depth and the VMCM depths, respectively; and $\tau$ were obtained from nearby NDBC buoys. Rms values of $\Delta u_{\mathrm{log}}$ range from a low of $1.1 \mathrm{~cm} \mathrm{~s}^{-1}$ for ARG-ARMI, where the radar look direction is perpendicular to the mean wind direction, to a high of $4.5 \mathrm{~cm} \mathrm{~s}^{-1}$ for ARG-SMIN, where the radar look direction is parallel to the mean wind direction. These correspond to $10 \%$ of $\Delta V_{\mathrm{rms}}$ for ARG-ARMI and $24 \%$ for ARG-SMIN. Rms values of $\Delta u_{\text {log }}$ explain $22 \%$ of $\Delta V_{\mathrm{rms}}$ on average. The exception is PTC-SMIN, where the rms of $\Delta u_{\text {log }}$ was about half of $\Delta V_{\text {rms }}$. In a study of near-surface shear in upwelling regimes, Lentz (1992) found that observed downwind shears were larger than predicted by this model. At the ADCP mooringobserved shear also exceeded predictions with (6), using 3 - and 8-m depths. Thus, $\Delta u_{\log }$ probably underestimates the actual shear, suggesting that wind induced shear represents a significant portion of $\Delta V_{\mathrm{rms}}$.

The study region is also subject to substantial swell. Mean wave heights at NDBC 54 during the study were $2.8 \pm 0.8 \mathrm{~m}$, with mean dominant periods $11.6 \pm 3.7 \mathrm{~s}$. Using available spectral wave data collected with a Datawell Directional Waverider buoy near Point Conception (deployed by the California Data Information Program at CCS/SIO), Stokes drift $u_{s}$ at depth $z$ was estimated as

$$
u_{s}=\int a^{2} \sigma k e^{-2 k z} d T,
$$

where $a$ is the wave amplitude, $\sigma=2 \pi T^{-1}$ is the angular wave frequency, $k=\mathrm{g}^{-1} \sigma^{2}$ is the wavenumber, and $T$ 
is wave period. From 19 March 1998 through 30 November 1999, the mean Stokes drift at 1-m depth was $2.2 \mathrm{~cm} \mathrm{~s}^{-1}$, in the mean wave direction of $290^{\circ}$. This compares well with Stokes drift estimated by Richman et al. (1987) $\left(3 \mathrm{~cm} \mathrm{~s}^{-1}\right)$, and is larger than estimated by Graber et al. $(1997)\left(\sim 1 \mathrm{~cm} \mathrm{~s}^{-1}\right)$. The VMCM measurement may include an error $u_{m}$ due to wave-induced vertical mooring motions (Pollard 1973),

$$
u_{m}=\frac{1}{2} \int a^{2} \sigma k e^{-k z} d T .
$$

Over the same time period, $u_{m}$ was $0.7 \mathrm{~cm} \mathrm{~s}^{-1}$ using (9). Thus, the net wave-induced velocity difference in the mean wind and wave direction (bearing $\sim 290^{\circ}$ ) was $1.5 \mathrm{~cm} \mathrm{~s}^{-1}$. Wave-induced velocity differences are less important for radials aligned away from this bearing.

Graber et al. (1997) point out that measurements can differ due to horizontal separation between HF radar sectors and current meters locations. Sector sizes increase with range from the radars, which may account for the weak trend of increased $\Delta V_{\text {rms }}$ with range (Table 1, Fig. 1). When data from ARG are excluded, $r^{2}=$ $0.32(N=16)$ between $\Delta V_{\text {rms }}$ and range. The larger sampling area at greater range increases the likelihood of larger horizontal current variability within the sector. For our radar sites, sectors containing moorings had widths from 0.5 to $3.7 \mathrm{~km}$ corresponding to ranges of $5.7-42 \mathrm{~km}$. If a mooring was located near the edge of a given sector, the mooring and the center of the sector could have been as much as $\sim 2 \mathrm{~km}$ apart. Extrapolation from Fig. 10 of Graber et al. (1997) suggests an expected rms difference derived from OSCR total velocity data of about 5-6 $\mathrm{cm} \mathrm{s}^{-1}$ resulting from a horizontal separation of $2 \mathrm{~km}$ between measurements. Kosro (1987) computed the structure function of horizontal velocity differences using shipboard ADCP data in an upwelling regime. His results suggest an expected difference of 7 $\mathrm{cm} \mathrm{s}^{-1}$ for a $2-\mathrm{km}$ separation. These are only rough estimates since horizontal velocity differences are strongly dependent on the flow field.

Limited resolution of the HF radar's Doppler spectra also contributes to $\Delta V_{\text {rms }}$. The length of the time series used to compute Doppler spectra (256 s for these data) sets the radar's spectral resolution. This effectively limits the resolution of $V_{\mathrm{HF}}$ to discrete levels separated by $\Delta V_{\mathrm{HF}}=4.3 \mathrm{~cm} \mathrm{~s}^{-1}$. The conversion of continuous currents into discrete levels produces rms errors of $(1 / 12)^{1 / 2}$ $\times \Delta V_{\mathrm{HF}}=1.2 \mathrm{~cm} \mathrm{~s}^{-1}$ (Bendat and Piersol 2000), assuming the error has a uniform probability distribution. It also produces uncertainty in spectral levels (Fig. 5) corresponding to $3.1 \mathrm{~cm}^{2} \mathrm{~s}^{-2}(\mathrm{cph})^{-1}$, although this is well below observed HF radar noise level at high frequency.

Part of $\Delta V_{\text {rms }}$ in Table 1 results from white noise in the HF radar current data, the high-frequency portion of which is evident in $V_{\mathrm{HF}}$ spectra (Figs. 5a,b). The source of this high-frequency noise is the subject of a
Ph.D. dissertation by one of the authors (JAH), and preliminary evidence suggests both geophysical and instrument sources. However, results of Laws et al. (2000) suggest at least part of the noise results from the MUSIC algorithm and depends on the transmit frequency. For 13.4-MHz transmit frequency, they estimate $1-2 \mathrm{~cm} \mathrm{~s}^{-1}$ rms error, compared to the $6 \mathrm{~cm} \mathrm{~s}^{-1}$ rms error estimated from $V_{\mathrm{HF}}$ spectra in Fig. 5. High-frequency noise in rotary spectra is also observed, despite substantial spatial averaging (Fig. 5c). [An average (standard deviation) of 18 (4) radial velocity measurements went into each hourly total vector data point.] This is coincident with the low $\gamma^{2}$ at high frequency for $U, V$ components between the radars and mooring (Fig. 6c).

\section{c. Bearing offset}

In a previous study comparing OSCR measurements with ADCP data from 7-m depth, Kosro et al. (1997) found that the maximum correlation occurred at a radar cell other than the one lying directly over the mooring. This is consistent with the CODAR SeaSonde bearing offset we observed. Bearing offsets may have several causes, such as antenna pattern distortions, phase calibration of the receive antenna elements, and, in this case, limitations of the MUSIC algorithm. Other easily dismissed explanations include misalignment of the receive antenna and compass errors in the mooring current meters. Misalignment of the receive antenna would result in constant $\Delta \theta$ at each mooring azimuth around a given radar. Table 1 shows that this is not the case: $\Delta \theta$ varies in magnitude and sign for each mooring-radar pair. Also, repeated checks indicated antenna alignments are constant in time to within $\sim 1^{\circ}$. Similarly, current meter compass error cannot the explain variation of $\Delta \theta$ with bearing. If compass error alone accounted for $\Delta \theta$, then pairs using the same VMCM would show similar $\Delta \theta$. Table 1 shows this is not true: for example, for the FBKSAOF pair $\Delta \theta=-8^{\circ}$, but for ARG-SAOF $\Delta \theta=19^{\circ}$.

A possible explanation of nonzero $\Delta \theta$ is given by Barrick and Lipa (1986), who examined the influence of antenna patterns on radial currents. Antenna patterns describe the directional response of the receive antenna to incoming HF radiation. Ideally, only the antenna's design determines the antenna pattern. However, the patterns are also affected by conductors in the near field, the area within about one wavelength of the antenna $(\sim 25 \mathrm{~m})$. These conductors couple with the antenna, distorting the antenna pattern. For example, Barrick and Lipa (1986) found severely distorted antenna patterns during a deployment on an offshore oil platform, with rms bearing errors $\sim 35^{\circ}$. Antenna pattern distortions can now be accounted for in the MUSIC algorithm; however, during the data collection phase of this study corrections were unavailable and ideal patterns were assumed in processing.

To test the assumption of ideal patterns, antenna patterns at PTC, RFG, and COP were measured by moving 
a transponder in a small boat along circular arcs within the coverage areas of the radars. Antenna patterns measured at RFG and PTC (data not shown) were typical of patterns found at sites in other regions, exhibiting low levels of distortion, while patterns at COP were moderately distorted (D. Barrick 1999, personal communication).

Measured antenna patterns were compared with $\Delta \theta$ to look for a relationship between distortions in the patterns and nonzero values of $\Delta \theta$. For example, following a suggestion by J. Paduan (2000, personal communication), a relationship between $\Delta \theta$ and the rate of change of the measured antenna pattern versus bearing was investigated but none was found. Large $\Delta \theta$ occurred both with and without corresponding distortions in antenna patterns.

An important part of the antenna pattern measurement, which may account for nonzero $\Delta \theta$, is the phase calibration of the three-element receive antenna. Each of the two-loop antenna elements responds to incoming signals with differing voltage phases depending on signal direction. Phase calibrations were initially determined at PTC from sea echo as part of the CODAR data processing procedures (Barrick and Lipa 1986). For comparison, phases were also directly measured with the transponder. Lower $\Delta \theta$ between PTC and SMIN was found when the transponder-derived phases were used $\left(\Delta \theta=15^{\circ}\right)$, compared with the sea echo-derived phases $\left(\Delta \theta=30^{\circ}\right)$. The reduction in $\Delta \theta$ indicates a strong link between receive antenna characteristics and $\Delta \theta$.

Nonzero $\Delta \theta$ may also result from limitations of the MUSIC algorithm. Laws et al. (2000) note that oceanographic application of MUSIC for bearing determination requires assumptions about the flow field. For example, for a three-element receive antenna such as the CODAR SeaSonde's, MUSIC assumes that the same radial velocity occurs in no more than two sectors within a range cell. Flow conditions that invalidate this assumption in the mean may result in $\Delta \theta$. However, the relative magnitude of this effect compared with the effect of assumed ideal antenna patterns is not clear. Much needs to be learned about how MUSIC is affected by factors such as antenna characteristics and flow conditions.

The effect of $\Delta \theta$ on total velocity vectors, determined from two radars, was examined using simple flow patterns. In one example, a uniform westward flow along a straight coastline was assumed (black arrows, Fig. 9). Here $V_{\mathrm{HF}}$ as functions of range and bearing were computed from the uniform flow at two sites, labeled A and $B$ in Fig. 9. At site A, bearings to sectors on the sea surface were distorted using a linear least squares fit for $\Delta \theta$ observed at the PTC radar. To actual bearings at A, ranging from $90^{\circ}$ to $270^{\circ}, \Delta \theta$ was added between $-18^{\circ}$ and $14^{\circ}$ as found for PTC (Table 1 ). Total velocity vectors (gray arrows, Fig. 9) were then computed from $V_{\mathrm{HF}}$ at sites $\mathrm{A}$ and $\mathrm{B}$. The mean error in flow speeds between the original vectors (black arrows, Fig. 9) and distorted

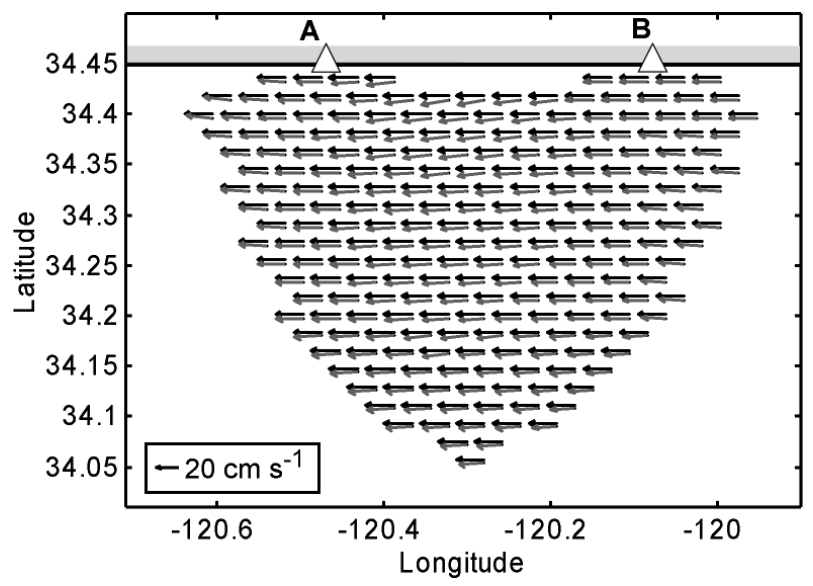

FIG. 9. Black arrows (offset for clarity) parallel to a straight coastline (bold line and shading), show uniform westward flow used for modeling effects of bearing offset $\Delta \theta$ on total velocity vectors. Gray arrows show total vectors computed from radar sites, located at A and $\mathrm{B}$ (triangles). Radial currents $\left(V_{\mathrm{HF}}\right)$ at $\mathrm{A}$ were distorted using the bearing offset $\Delta \theta$ observed at PTC. Arrows are placed on grid with 4-km spacing.

vectors (gray arrows, Fig. 9) was $\sim 7 \%$ of the original uniform flow speed with a maximum error of $\sim 15 \%$. The mean error in flow direction was $\sim 2.5^{\circ}$, with a maximum of $\sim 9^{\circ}$. Simulations with other simple flow fields produced comparable errors in total velocities (results not shown). These errors illustrate the effect of bearing offsets $(\Delta \theta)$ on the total velocity data, and the need to understand and correct errors in direction finding.

\section{Conclusions}

Radial components of near-surface ocean currents (radials) were compared from $18 \mathrm{HF}$ radar-moored current meter pairs in the Santa Barbara Channel and Santa Maria basin. Comparisons were based on observations between 1 August 1997 and 15 November 1999 with record lengths of 5-424 days. Eight vector-measuring current meters moored at 5-m depth and one ADCP with its shallowest bin at $3.2 \mathrm{~m}$ were compared with HF radar currents at $\sim 1 \mathrm{~m}$. The analysis supports the following conclusions.

1) Radials obtained from the radars were significantly correlated with radials obtained from the moored current meters with $r^{2}$ in the range $0.39-0.77$. Rms radial speed differences ranged from 7 to $19 \mathrm{~cm} \mathrm{~s}^{-1}$. A weak trend of increasing rms difference was found with increasing range.

2) Significant coherence was found between current meter and radar-derived time series for frequencies below $0.1 \mathrm{cph}$ (10-h period and longer). Power spectra show similar magnitudes and slopes for frequencies below $0.1 \mathrm{cph}$. At high frequency, a $6 \mathrm{~cm} \mathrm{~s}^{-1}$ rms noise level was present in the radar measurement. 
3) A pointing error $\Delta \theta$ ranging from $-16^{\circ}$ to $19^{\circ}$, where positive values indicate a clockwise error, was found for some of the radars; $\Delta \theta$ for a given radar was not constant, but varied with bearing. We speculate that $\Delta \theta$ resulted from distortions of the receive antenna patterns in the near field, but results of comparisons between $\Delta \theta$ and measured patterns were inconclusive. Other possible sources include phase calibration settings and properties of MUSIC.

4) A simple empirical model of $\Delta \theta$ versus bearing was used to simulate errors in total velocity vectors computed from two radars. Using a uniform flow parallel to shore, $\Delta \theta$ produced speed errors of up $15 \%$ and direction errors up to $9^{\circ}$ in total velocity vectors.

Acknowledgments. This work benefited from the comments of two anonymous reviewers and discussions with Jeffrey Paduan, Michael Kosro, and Edwin Beckenbach. Don Barrick and Pete Lilleboe provided assistance with calibration, and advice on the operation of the radars. Programs written by Michael Cook aided data visualization and processing. David Salazar and Chris Gotschalk provided valuable support during field operations. We thank Clinton Winant, Edward Dever, Myrl Hendershott, and their colleagues at the Center for Coastal Studies at the Scripps Institution of Oceanography for use of the moored current data. The NOAA Environmental Technology Laboratory loaned the radars deployed at Fallback 22 and Point Arguello. This research was supported by the Minerals Management Service, U.S. Department of the Interior, MMS Agreement 14-35-0001-30758. Support was also provided by the W. M. Keck foundation and the David and Lucile Packard Foundation as part of the Partnership for Interdisciplinary Studies of Coastal Oceans (PISCO). Siting the radars was made possible through the cooperative agreements with the California State Parks Channel Coast District, the United States Coast Guard, and the United States Air Force. The views and conclusions contained in this document are those of the authors and should not be interpreted as necessarily representing the official policies, either expressed or implied, of the U.S. government.

\section{REFERENCES}

Barrick, D. E., and B. J. Lipa, 1986: Correcting for distorted antenna patterns in CODAR ocean surface measurements. IEEE J. Oceanic Eng., OE-11, 304-309.

—, and - 1997: Evolution of bearing determination in HF current mapping radars. Oceanography, 10, 72-75.

—_ M. W. Evans, and B. L. Weber, 1977: Ocean surface currents mapped by radar. Science, 198, 138-144.

Bendat, J. S., and A. G. Piersol, 2000: Random Data Analysis and Measurement Procedures. Wiley Interscience, $594 \mathrm{pp}$.

Bjorkstedt, E., and J. Roughgarden, 1997: Larval transport and coastal upwelling: An application of HF radar in ecological research. Oceanography, 10, 64-67.

Broche, P., J. P. Salomon, J. S. Demaistre, and J. L. Devenon, 1986: Tidal currents in Baie de Seine: Comparison of numerical mod- eling and high-frequency radar measurements. Estuarine Coastal Shelf Sci., 23, 465-476.

Chapman, R. D., L. K. Shay, H. C. Graber, J. B. Edson, A. Karachintsev, C. L. Trump, and D. B. Ross, 1997: On the accuracy of HF radar surface current measurements: Intercomparison with ship-based sensors. J. Geophys. Res., 102 (C8), 18 737-18 748.

Collar, P. G., J. M. Howarth, N. W. Millard, and D. Eccles, 1985: An intercomparison of HF radar observations of surface currents with moored current meter data and displacement rates of acoustically tracked drogued floats. Evaluation, comparison and calibration of oceanographic instruments. Proceedings of an international conference, Advances in Underwater Technology and Offshore Engineering, Graham \& Trotman, 163-182.

Crombie, D. D., 1955: Doppler spectrum of sea echo at $13.56 \mathrm{Mc} / \mathrm{s}$. Nature, 175, 681-682.

Davies, K., 1990: Ionospheric radio. IEEE Electromagnetic Waves Ser., 31.

Dorman, C. E., and C. D. Winant, 2000: The structure and variability of the marine atmosphere around the Santa Barbara Channel. Mon. Wea. Rev., 128, 261-282.

Essen, H.-H., K.-W. Gurgel, and F. Schirmer, 1989: Surface currents in the Norwegian Channel measured by radar in March 1985 . Tellus, 41A, 162-174.

Frisch, A. S., and B. L. Weber, 1980: A new technique for measuring tidal currents by using a two-site HF Doppler Radar System. J. Geophys. Res., 85 (C1), 485-493.

Gonella, J., 1972: A rotary-component method for analysing meteorological and oceanographic vector time series. Deep-Sea Res., 19, 833-846.

Graber, H. C., and C. B. Limouzy-Paris, 1997: Transport patterns of tropical reef fish larvae by spin-off eddies in the Straits of Florida. Oceanography, 10, 68-71.

— B B. K. Haus, R. D. Chapman, and L. K. Shay, 1997: HF radar comparison with moored estimates of current speed and direction: Expected differences and implications. J. Geophys. Res., 102 (C8), $18749-18766$.

Gurgel, K. W., 1994: Shipborne measurement of surface current fields by $\mathrm{HF}$ radar. L'Onde Electrique, $\mathbf{7 4}, \mathbf{5 4 - 5 9 .}$

— , G. Antonischski, H.-H. Essen, and T. Schlick, 1999: Wellen radar (WERA): A new ground wave radar for remote sensing. Coastal Eng., 37, 219-234.

Hammond, T. M., C. Pattiaratchi, D. Eccles, M. Osborne, L. Nash, and M. Collins, 1987: Ocean surface current radar vector measurements on the inner continental shelf. Contin. Shelf Res., 7, $411-431$.

Harlan, J. A., S. E. Swearer, R. R. Leben, and C. A. Fox, 2002: Surface circulation in a Caribbean island wake. Contin. Shelf Res., 22, 417-434.

Harms, S., and C. D. Winant, 1998: Characteristic patterns of the circulation in the Santa Barbara Channel. J. Geophys. Res., 103 (C2), 3041-3065.

Hodgins, D. O., 1994: Remote sensing of ocean surface currents with the SeaSonde HF radar. Spill Sci. Technol. Bull., 1, 109-129.

Holbrook, J. R., and A. S. Frisch, 1981: A Comparison of near-surface CODAR and CACAM measurements in the Strait of Juan De Fuca, August 1978. J. Geophys. Res., 86 (C11), 10 908-10 912.

Janopaul, M. M., P. Broche, J. C. de Maistre, H. H. Essen, C. Blanchet, G. Grau, and E. Mittelstaedt, 1982: Comparison of measurements of sea currents by HF radar and by conventional means. Int. J. Remote Sens., 3, 409-422.

Kohut, J., S. Glenn, and D. Barrick, 1999: SeaSonde is integral to coastal flow model development. Hydro Int., 3, 32-35.

Kosro, P. M., 1987: Structure of the coastal current field off northern California during the coastal ocean dynamics experiment. $J$. Geophys. Res., 92 (C2), 1637-1654.

_ _ J. A. Barth, and T. P. Strub, 1997: The coastal jet: Observations of surface currents over the Oregon continental shelf from HF radar. Oceanography, 10 (2), 53-57.

Laws, K. E., D. M. Fernandez, and J. D. Paduan, 2000: Simulation- 
based evaluations of HF radar ocean current algorithms. IEEE J. Oceanic Eng., 25, 481-491.

Lentz, S. J., 1992: The surface boundary layer in coastal upwelling regions. J. Phys. Oceanogr., 22, 1517-1539.

Melton, D. C., 1995: Remote sensing and validation of surface currents from HF radar. M.S. Thesis, Naval Postgraduate School, $66 \mathrm{pp}$.

Paduan, J. D., and L. K. Rosenfeld, 1996: Remotely sensed surface currents in Monterey Bay from shore-based HF radar (Coastal Ocean Dynamics Application Radar). J. Geophys. Res., 101 (C9), 20 669-20 686.

- D. Barrick, D. Fernandez, Z. Hallock, and C. Teague, 2001: Improving the accuracy of coastal HF radar current mapping. Hydro Int., 5, 26-29.

Pollard, R., 1973: Interpretation of near-surface current meter observations. Deep-Sea Res., 20, 261-268.

Prandle, D., S. G. Loch, and R. Player, 1993: Tidal flows through the Straits of Dover. J. Phys. Oceanogr., 23, 23-37.

Richman, J. G., R. A. de Szoeke, and R. E. Davis, 1987: Measure- ments of near-surface shear in the ocean. J. Geophys. Res., 92 (C3), 2851-2858.

Schmidt, R. O., 1986: Multiple emitter location and signal parameter estimation. IEEE Trans. Antennas Propag., AP-34, 276-280.

Schott, F. A., S. A. Frisch, and J. C. Larsen, 1986: Comparison of surface currents measured by HF Doppler Radar in the Western Florida straits during November 1983 to January 1984 and Florida current transports. J. Geophys. Res., 91 (C7), 8451-8460.

Shay, L. K., H. C. Graber, D. B. Ross, and R. D. Chapman, 1995: Mesoscale ocean surface current structure detected by high-frequency radar. J. Atmos. Oceanic Technol., 12, 881-900.

- S. J. Lentz, H. C. Graber, and B. K. Haus, 1998: Current structure variations detected by high-frequency radar and vectormeasuring current meters. J. Atmos. Oceanic Technol., 15, 237256.

Stewart, R. H., and J. W. Joy, 1974: HF radio measurements of surface currents. Deep-Sea Res., 21, 1039-1049.

Weller, R. A., and R. E. Davis, 1980: A vector measuring current meter. Deep-Sea Res., 27, 565-582. 